\title{
The analysis of several realistic problems of rural e-commerce Lei Wang
}

\author{
Business School, Yantai Nanshan University, Yantai, 265713, China
}

\author{
Keywords: Rural e-commerce, Current situation, Realistic problem, Measure
}

\begin{abstract}
With the continuous improvement of the technological and economic level, the living standards of rural residents have been significantly improved, and the application of computer and other high-tech products in rural areas is becoming more and more widely used.Faced with such situation, many people found the business opportunities, the rural e-commerce developed rapidly. But in the process of continuous development, rural e-commerce also met a lot of realistic problems, the existence of these problems seriously hampered the development of e-commerce.In this paper, we had analyzed the realistic problems in the process of development of rural e-commerce, and put forward our own solutions, hoped to contribute to the further development of rural e-commerce.
\end{abstract}

\section{Introduction}

Whether the economy or the culture in rural areas, the speed of development is relatively slower than the city's, so it determined the low extent of accepting new things in rural areas.The development of e-commerce in the city had gradually became saturated. In this case, many people looked on the rural market, which had great potential.Therefore, the development of rural e-commerce was very fast, but in the process of its development, the rural characteristics areas also increased the difficulty of the development of the e-commerce. How to solve the problems encountered in the development of the e-commerce, and promoted the further development of the e-commerce, had became the current focus of attention.

\section{The current situation of the development of the rural e-commerce}

In our country, the rapid development of the e-commerce in the city, made it very difficult to get breakthrough. In order to a better development of the e-commerce, many people looked on the rural market, which leads to the progress in the development of e-commerce in the countryside gradually accelerated, the number of rural website had increased significantly, and the e-commerce platform also gradually built up. From the view of overall development, the rural e-commerce of China is in the initial stage.Compared with the urban perfect e-commerce, there was a big gap, still needed to work hard. In construction of e-commerce in the rural of China, we must first do a good job of environmental construction, on the base of a right environment for the development of e-commerce, introduced all the technology the development of e-commerce needed. In efforts of development of the e-commerce, at the same time, the country also had given strong support that the state had set up the agricultural database. Through the effective application of the database, can improve the accuracy of the data collection and analysis of data, so as to provide reliable data support for the development of e-commerce.The data information helped business development and the agricultural research, but it was no value at all for the farmers.to give full play of the data value,the relevant departments must efficient handling the data, distributing the handled information to farmers, in order to realize the value of information, farmers needed to apply the information ${ }^{[1]}$. But in actual work, the processed information did not distributed to farmers, mainly because of the lack of rural information service platform, rural residents did not have the correct understanding of the e-commerce, in order to improve this situation, we must expand the propaganda of e-commerce, let farmer in-depth understanding of e-commerce, promoted the development of e-commerce, and obtained valuable information for their own on the base of this. 


\section{Problems encountered in the development of rural e-commerce}

\section{The lack of awareness of the e-commerce of rural residents}

The rapid development of science and technology in our country, made the Internet thinking popular in the city, and the e-commerce philosophy also known to everyone. When urban residents had been familiar with these information, rural business just started, which led to business philosophy as well as the Internet technology was a new thing for rural residents.The lack of knowledge of rural residents on the e-commerce, made them could not really understand meaning of the e-commerce presenting. In the process of the development of e-commerce in rural, many people just knew the name, not clear about the real meaning of the name, which had a negative impact on the development of the e-commerce. The pioneers of carrying out rural e-commerce, also had a wrong understanding of e-commerce. some people developed e-commerce as an independent industry, overlooked the combination with industrial entities, eventually leading to the business enterprise was unable to continue; another part looked the e-commerce as one of the means of marketing, only attached importance to marketing and ignored the existing industry, resulting the industry could not survive in the cruel competition environment.

\section{The consumption of rural residents was relatively backward.}

Rural residents were deeply influenced by the traditional consumption concept, in the process of consumption, they were used to the trading manner that I gave you money,you gave me goods. And there was a great difference between the consumption mode of e-commerce with the traditional consumption mode, farmers were not accustomed to this kind of consumption style, it was difficult for farmers to accept this new way of consumption and it needed to be unconsciously influenced, under the long-term effects, farmers would gradually accepted it, and applied the new consumption patterns in their life. ${ }^{[2]}$ Because the regional economic difference is big, the consumption concept of all the area was also different, in rural areas with a higher economic level,it was relatively easy to accept the consumption concept, but in the areas with lower economic lever, it was more difficult.

\section{The relative lack of talents of e-commerce}

In the process of development of e-commerce in rural, the problem of lacking talent was very important, if there is no e-commerce talents, the development of e-commerce would be impeded, which was bad for the long-term development of e-commerce. At present, the shortage of talents in our country was widespread. Not only for e-commerce, but also other industries, the talent problem had become a key issue urgently needed to be solved in the current state.According to the study, at present the e-commerce still needed about 150 million personnel, with the continuous development of e-commerce, the demand for talents would exceed 200 million, the most scarce of which was that data analysis, operation promotion and artist three kinds of talents. In rural areas, the large shortage of e-commerce talents, led to the development of e-commerce could not be fully developed, and there were many problems in the existing e-commerce enterprises. In twenty-first Century, the problem of talent would be one of the main factor restricting the further development of the e-commerce.

\section{The number of rural websites was small and the distribution was unbalanced, and the utilization rate was low.}

According to the survey, the number of rural websites was small and the distribution was unbalanced, and the utilization rate was low in China. The majority of Internet users and agricultural websites were distributed in cities with high economic levels, especially in the eastern developed regions. In the area with low economic levels, the Internet users were less and the number of rural websites was significantly fewer than that of the developed areas in the economy. The technological level was lower in the area with low economic levels. At the same time, the utilization level of rural websites in our country was not high. Agricultural website was mainly built for rural residents, urban residents had less concerned, but rural residents were restricted by the cultural level, so the utilization level of agricultural website was not high, it could not fully play its role. In our country, the agriculture website could be divided into the following several types: first, web site set up by the 
relevant government departments; second, website set up by the higher agricultural colleges and agricultural scientific research units, this kind of website not only included the wide scope, but also higher professional; third, website established by all kinds of industries; fourth, website established by individual, the number of this kind of website is less; fifth, established agricultural information column in some other type of website. ${ }^{[3]}$

\section{Without sound logistics distribution network}

The economic level of our country was lower than the city's, and it was not convenient for the traffic, which caused that it was difficult to effectively carry out the rural logistics distribution work . At present, many logistics company's distribution network covered only to the county, rural areas below the county level was unable to implement logistics distribution, in some remote and poor transportation area, it was unable to implement logistics distribution. The logistics distribution network was not perfect, which is also an important factor in restricting the development of e-commerce.In the process of the continuous development of e-commerce in the countryside, some farmers wanted to buy some products, but because the logistics could not distribute, leading to the e-commerce needs of farmers could not be met, the e-commerce business lost potential customers.Faced with such situation,the further development of e-commerce, we must establish a sound distribution network, realize that bought namely delivered, thereby broadening rural e-commerce market.

\section{Brand problems in the process of development of the e-commerce}

With the continuous development of the e-commerce in rural areas, sell more and more goods. If businesses could not take an innovative means, to create a distinctive brand, in the cruel competition environment, only by lower cost ways to broaden the sales channels, although with this approach you can attract some customers, but at the same time, it greatly reduce the profits of goods, is a "one thousand enemy, since the loss of eight hundred" for the businesses. In a long time developing, the businessman would eventually failed. The e-commerce factory put agricultural products onto the network, bu means of network marketing to sale agricultural products, but in the process of sales , because businesses do not have the thorough understanding of the characteristics of agricultural products, resulting in lower actual profit of selling goods, could only be hard to maintain development, not to obtain economic benefits. ${ }^{[4]}$ At present, there were two main types of agricultural products selling on the Internet,one is a kind of dry goods,such as red jujube,walnut,etc.,these dry cargoes were the same as ordinary storage products, had no outstanding characteristics,businesses could only sold it at low prices,earned a little profit; The other is fresh food, while the gross profit of selling fresh food was high, but the transportation cost and the loss cost were also high,on average,the profit was not high. In such situation, businesses must establish a characteristic brand, only in this way could expand the scope of sales, to get more profits.

\section{To solve the problem of rural e-commerce}

\section{To cultivate e-commerce talents, improve the overall quality of rural residents}

The purpose to establish the agricultural website was to provide some information for farmers and help farmers better farming, but the base of these information worked is in farmer's use, if farmers were not using these information, the information could not reflect their own value. Therefore, effective measures must be taken to improve the utilization of agricultural website information in rural areas. At the same time, in order to promote the development of rural e-commerce, we must solve the problem of the shortage of talents, and vigorously cultivate professional e-commerce talents.Training e-commerce talents, improving the quality of the residents could start from the following aspects: first, training the residents, so that the rural residents learned to use the computer. Computer is the carrier of agricultural websites and commercial sales of products, to improve the utilization rate of farmers using the website information , promote business development, must teach the farmers to use computer, after mastering the basic skills, farmers were allowed to browse the site, 
and told them that the site information could help them to improve their economic income, in order to attract farmers, made them focus the site; Second, focus on supporting a number of rural residents with e-commerce operation ability, by the means of letting them get rich first, interesting other farmers in e-commerce and encouraging them to actively study the relevant knowledge, so as to improve all farmers' income ${ }^{[5]}$; Third, to formulate preferential policies. The Country formulated a series of preferential policies for rural e-commerce, to attract more people to set their sights on the rural market, encourage some professional e-commerce talents to carry out the work in rural areas, so as to promote the development of rural e-commerce.

\section{Vigorously develop the rural economy}

The primary cause of rural residents consumption idea relatively backward was that the economic level of rural residents was not high, if you want to change the consumption concept of the rural residents, the state must vigorously develop the rural economy, to take effective measures to improve the income of rural residents and farmers had money, would naturally want to consume.Therefore, to drive the further development of rural e-commerce, promote the development of rural economy, improving the economic income of rural residents was the most effective measures.

\section{To establish a sound logistics distribution network system}

In order to promote the development of e-commerce in the countryside, it was necessary to set up a perfect logistics distribution network system. It had all kinds of agricultural products in our country, but the production unit was small, the family was as the base of the main body, which led to the low degree of organization of agricultural products, a wide range of distribution, so that it increased the difficulties of distribution. Faced with such situation, businesses can deeply research the distribution problem, harmonizing products through the use of advanced means and network technology, establishing high-efficiency and modern logistics distribution system. At the same time, it should take effective measures to optimize the distribution of resources, reduce distribution costs, so as to realize the logistics distribution and delivery, and promote the development of rural e-commerce.

\section{Developing characterized brand agriculture}

In the process of continuous development of rural e-commerce, the competition in rural market was increasingly fierce, business enterprise wanted to survive in the cruel competition environment, must create characterized brand, so that we could gain a firm foothold in the limited market. Under the condition of the rural e-commerce,we could put the construction of appealing to market demand with characteristics of the industrial system first of the development, standardized production, continuously improved the quality of the products, so as to break the industry bound, put the high quality of agricultural products towards high quality region, forming industrial clusters with high-quality characteristic.At the same time, it could also improve the practicality of the site, increase some timeliness information, further improve the level of the site. In order to develop characteristic brand agricultural, the state should also formulate further preferential policies, through preferential policies to attract more investors and encourage more enterprises to participate in the construction of website of e-commerce.

\section{Conclusion}

In rural areas the development of e-commerce had a role in promoting the development of rural areas. E-commerce could not only expand the rural market, adjust the industrial structure, but also could reduce the cost, make rural residents to keep pace with the times. At the same time, it also increased the income of the farmers, shortens the gap between urban and rural residents, and greatly promotes the overall development of rural economy in China.

\section{References}

[1] Wei Yan’an. Seven practical problems of rural e-commerce.Village director,2014(11):36-37. 
[2] Fang Cheng.Research on the development of rural e-commerce market.Logistics technology and Application,2014,19(11):134-136.

[3] Wei Yan'an. Four major performance of the development of rural e-commerce.Agricultural knowledge (rural monsoon),2014(11):1.

[4] Lin Jie. Research on the development status of rural e-commerce.Southern agricultural machinery,2015(1):94-95.

[5] Xie Xinhua.Research on the development of rural e-commerce logistics based on the long tail theory in China.E-commerce,2013(7):19-20. 